\title{
Further Analysis of Burkholderia pseudomallei MF2 and Identification of Putative Dehalogenase Gene by PCR
}

\author{
Mohamed Faraj Edbeib ${ }^{1,2, *}$, Roswanira Abdul Wahab ${ }^{3}$, Fahrul Huyop ${ }^{3,4 *}$, \\ Hasan Murat Aksoy ${ }^{2}$, and Yilmaz Kaya ${ }^{5,6}$ \\ ${ }^{1}$ Department of Animal Production, Faculty of Agriculture, Baniwalid University, Libya \\ ${ }^{2}$ Department of Plant Pathology, Faculty of Agriculture, Ondokuz Mayis University, 55100 Samsun, Turkey \\ ${ }^{3}$ Department of Chemistry, Faculty of Science, Universiti Teknologi Malaysia, 81310 UTM Johor Bahru, Malaysia \\ ${ }^{4}$ Department of Biosciences, Faculty of Science, Universiti Teknologi Malaysia, 81310 UTM Johor Bahru, Malaysia \\ ${ }^{5}$ Department of Agricultural Biotechnology, Faculty of Agriculture, Ondokuz Mayis University, 55100 Samsun, Turkey \\ ${ }^{6}$ Department of Biology, Faculty of Science, Kyrgyz-Turkish Manas University, Kyrgyzstan
}

* Corresponding author:

tel: $+607-55334148$

email:faemohamed2@live.utm.my*;

fahrul@utm.my

Received: February 2, 2019

Accepted: August 1, 2019

DOI: $10.22146 /$ ijc. 43262

\begin{abstract}
Halogenated organic compounds are extensively and widely used as pesticides, herbicides, and antibiotics that contribute to the pollution. This research was aimed to further analyze and characterize a bacterium that has the ability to utilize 2,2dichloropropionic acid (2,2-DCP) as a model to study dehalogenase enzyme production. Microscopic observation, biochemical tests and PCR technique were carried out in order to characterize the isolated bacterium. Strain MF2 showed its ability to grow on $10 \mathrm{mM}$ 2,2-DCP liquid minimal medium with doubling time of $13 \mathrm{~h}$ with maximum chloride ion released of $19.8 \mathrm{\mu molCl}^{-} / \mathrm{mL}$. The $16 \mathrm{~S} \mathrm{rDNA}$ analysis suggested that strain MF2 belongs to the genus Burkholderia. This was supported by the microscopic observation and biochemical tests. Dehalogenase gene was observed when using only primers dehI $I_{\text {for } 1}$ and deh $I_{\text {rev } 2}$ derived from group I deh PCR primer sequences, whereas no amplification using dhlB-314-forward and dhlB-637-reverse (group II dehalogenase) and haloacetate dehalogenase (H2-1157-forward and H2-1662-reverse) PCR primer sequences. The results suggested that, possibly, dehalogenase from MF2 was related to group I deh. In conclusion, strain MF2 showed the ability to utilize 2,2-DCP as sole source of carbon and energy. Further analysis revealed the MF2 strain consisted of dehalogenase gene that could be used for degradation of man-made halogenated compounds present in the environment. Using existing dehalogenase PCR primers, it was possible to amplify the dehalogenase genes sequence.
\end{abstract}

Keywords: Burkholderia pseudomallei; 2,2-dichloropropionate; biodegradation; dehalogenase gene; $16 S$ rDNA gene

\section{- INTRODUCTION}

Environmental contamination from industrial chemicals, herbicide or pesticide from agricultural activities is an ongoing dilemma to the society. 2,2dichloropropionate (abbreviation known as 2,2-DCP) or Dalapon $^{\circledast}$ is a synthetic halogenated compound used in herbicides. The demand for herbicide in agriculture is increasing and its use is inevitable to improve crop yields in many developing countries. In some areas like in the Pineapple Plantation, Pekan Nenas Johor, Malaysia, it is believed that herbicide use will solve all weed problems. Xenobiotic compounds, mostly man-made chemicals when present in high concentrations in the environment can be very hazardous to the ecosystem and some resistant to degradation [1]. Among these xenobiotics, halogenated compounds are considered very toxic and

Mohamed Faraj Edbeib et al. 
may cause enormous problems to human health and the environment. However, the answer to such predicament perhaps lie in the very ground we stand on. It is believed that microorganisms are capable of degrading xenobiotics [2-3].

Soil microorganisms such as Rhizobium sp., Methylobacterium sp. HJ1 and Arthrobacter sp. have been reported to be capable of utilizing such compounds as their sole carbon source for growth while liberating the organically bound chlorine as chloride ions at the same time [4-6]. The molecular structure of the 2,2-DCP consists of three carbons with the molecular formula $\mathrm{CH}_{3} \mathrm{CCl}_{2} \mathrm{CO}_{2} \mathrm{H}$ (Fig. 1). The first carbon is a carboxylic functional group $(-\mathrm{COOH})$ and followed by two chloride substituents at $\mathrm{C}-2$ of $\alpha$ carbon position. From chemistry point of view, the $\alpha$-chlorination is particularly important within the halogenated propionic series because it results in herbicidal activity. Acids chlorinated in other positions do not possess phytotoxic properties unless they are also a-chlorinated. Similarly, increasing chain length reduces the herbicidal activity of the $\alpha$-chloroacids, for instance 2,2-dichlorohexanoic acid being completely inactive. It has been reported that substitution of other halogens for chloride generally decreases herbicidal activity of these acids [7].

Biodegradation using microorganisms is one of the main and natural processes that help remove xenobiotic chemicals such as chloroaliphatic compounds from the environment [8-9]. Also, microorganisms can benefit from the use of the contaminant as an electron donor and carbon source to support growth. Hydrolytic dehalogenases represent the key position in the degradation of haloaliphatic compounds. These enzymes catalyze the cleavage of carbon-halogen bonds by nucleophilic substitution, replacing the halogen ion by a hydroxyl group derived from water [10]. Dehalogenase enzymes metabolize chlorinated substituents and the halogens are enzymatically removed to form non-halogenated compounds. In cases where biodegradation of halogenated compounds are lacking, it is often due to the inability of microorganisms to effectively metabolize such compounds with chemical structures to which these microbes have yet to be exposed during the course of evolution. In other words, recalcitrance

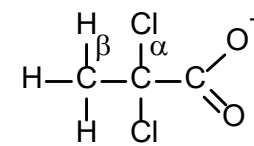

Fig 1. Basic structure of 2,2-DCP

of certain halogenated compounds generally is the result of a lack of efficient metabolic pathways. Nevertheless, there are reports of many microorganisms that have the ability to metabolize xenobiotic organohalogens [8]. This led to the idea that such microorganisms must have evolved their catabolic pathways during the past few decades and is thus suited to study the natural assembly of catabolic routes.

According to Slater et al. [11], dehalogenases can be classified based on substrate specificities. On the other hand, Hill et al. [12] classified dehalogenases based on genetic approach by investigating the diversity and molecular ecology of the dehalogenase genes. Using phylogenetic classification, dehalogenase is divided into group I and group II. These two families are evolutionarily unrelated and together represent almost all of $\alpha$-halocarboxylic acid ( $\alpha \mathrm{HA}$ ) deh genes as described. Group I is a non-stereospecific dehalogenase which act on C2-halogenated short chain aliphatic acids including D-isomer and L-isomer. For example, group I dehalogenases are able to act on $\mathrm{D}$-2-chloropropionic acid (D-2-CP), L-2-chloropropionic acid (L-2-CP), D,L2-chloropropionic acid (D,L-2-CP) and 2,2-DCP. Meanwhile, dehalogenases of group II is stereospecific that acts only on L-2-CP but not D-2-CP and 2,2-DCP [12]. Other kinds of dehalogenases, termed haloacetate dehalogenase (EC 3.8.1.3) that acts specifically on halogenated acetates to yield glycolate, are also in group II [13]. To understand how these dehalogenases function, in silico studies on enzyme-substrate binding need to be carried out provided that full dehalogenase sequence can be obtained in gene isolation by PCR [14-15].

Previous investigations have described that the molecular approach could be used to uncover genus/species and gene of interest like dehalogenase genes of the newly isolated microorganisms [16]. Therefore, the current study is focused on characterizing a bacterium isolated from mud soil from pineapple 
plantation that can degrade 2,2-DCP and amplification of the putative dehalogenase gene using dehalogenase degenerate primers. In the current investigation, strain MF2 was further characterized and its putative dehalogenase classification was then determined.

\section{- EXPERIMENTAL SECTION}

\section{Isolation}

The minimal growth media for growing bacteria was prepared as described by Hamid et al. [17]. Mud soil taken from a Pineapple agricultural area in Johor (10 g) was added into $250 \mathrm{~mL}$ conical flask containing $100 \mathrm{~mL}$ of minimal media with $10 \mathrm{mM}$ of 2,2-DCP as the sole carbon and energy source. The bacterial culture was incubated in an incubator shaker for $3-7$ days at $30{ }^{\circ} \mathrm{C}$. For solid medium, Oxoid bacteriological agar No.1 $(1.5 \% \mathrm{w} / \mathrm{v})$ was added prior to sterilization. Bacterial culture was streaked onto the agar plate containing the same ingredients as the liquid minimal media. One pure colony was obtained after several subcultures by streaking on solid minimal media. The bacterial strain was characterized via morphological/biochemical tests as described in Bergey's Manual of Systematic Bacteriology [18].

\section{Determination of Bacterial Growth}

The extent of growth was determined by measuring the absorbance at $A_{680 \mathrm{~nm}}$ and the release of chloride ions was measured at $A_{460 \mathrm{~nm}}$ [19]. Measurement of the free halide released during the dehalogenation reaction was carried out by an adaptation of the method of Bergmann and Sanik [20]. The chloride ion released was defined $1 \mathrm{mM}$ chloride is equivalent to $1 \mu \mathrm{mol} \mathrm{Cl}-/ \mathrm{mL}$.

\section{PCR Amplification of 16S rDNA Gene}

The chromosomal DNA was extracted using Qiagen DNA extraction kit as described by the manufacturer. PCR amplification was carried out using universal primers to amplify the $16 \mathrm{~S}$ rDNA gene as described by Fulton and Cooper [21].

\section{Partial Biochemical Tests}

Different types of biochemical tests were carried to ascertain the identity of the bacteria by carrying out spore staining, catalase test, urease test, oxidase test, lactose utilization test, indole test, gelatin hydrolysis, motility test and nitrate reduction test.

\section{PCR Amplification for Putative Dehalogenase Gene}

The source of the primers were obtained from group I deh PCR primer sequences dehI $\mathrm{I}_{\text {forl }}$ and dehI $\mathrm{I}_{\mathrm{rev} 2}$ [12], Xanthobacter autotrophicus (dhlB314 and dhlB 637) belonging to group II deh PCR primer sequences and Moraxella sp. for primers dehH2-1157 and dehH21662 of the haloacetate dehalogenase [22]. The PCR primers and PCR cycles are summarized in Table 1 and 2 , respectively.

Table 1. Dehalogenase oligonucleotide primers

\begin{tabular}{llll}
\hline Organisms & Genes & Primer sequences & Reference \\
\hline & Group I & dehI $_{\text {forl }}$ (Forward): & Hill et al. [12] \\
& Various sources & 5'-ACGCTGCGCGTGCCATGGGT-3' & \\
& & dehI Irev2 $_{\text {(Reverse): }}$ & van Der Ploeg et al. \\
& Group & II & 5'-CGCAATCACATGGAAGTCACT-3' \\
Xanthobacter & dehalogenase & dhlB-314 (Forward): & [22] \\
autotrophicus & & 5'-TCTGGCGGCAGAAGCAGCTGG-3' & \\
& & dhlB-637 (Reverse): & \\
& & 5'-CGCGCTTGGCATCGACGCTGATG-3' & Kawasaki et al. [13] \\
\hline Moroxella sp. & Haloacetate & dehH2-1157 (Forward): & \\
& dehalogenase H-2 & 5'-CGGCACCCTCTACGATGTGCATTCGG-3' & \\
& & dehH2-1662 (Reverse): & \\
& & 5'-CATCCCATGGATTCGACGATACAAAGA-3' & \\
\hline
\end{tabular}


Table 2. PCR cycles for amplification of putative dehalogenase gene

\begin{tabular}{cccc}
\hline Segments & Cycles & Temperature $\left({ }^{\circ} \mathbf{C}\right)$ & Duration \\
\hline 1 & 1 & 94 & $2 \mathrm{~min} 30 \mathrm{sec}$ \\
2 & 35 & 94 & $30 \mathrm{sec}$ \\
& & 55 & $30 \mathrm{sec}$ \\
& & 72 & $4 \mathrm{~min}$ \\
3 & 1 & 72 & $10 \mathrm{~min}$ \\
4 & 1 & 4 & $\infty$ \\
\hline
\end{tabular}

\section{DNA Sequencing and Molecular Analysis}

The PCR products were purified using Promega Wizard $^{\otimes}$ SV Gel and PCR Cleanup system. After purification, all PCR products were sent for sequencing at SOYGEN BIOTECHNOLOGY, Istanbul (Turkey).

\section{Scanning Electron Microscopy (SEM)}

Colonies of bacterial strain MF2 grown on solid media supplemented with 2,2-DCP for $24 \mathrm{~h}$ were excised as small agar blocks of $0.5 \mathrm{~cm}^{3}$. The colonies were pre-fixed with $25 \%$ glutaraldehyde in $100 \mathrm{mM}$ phosphate buffer ( $\mathrm{pH}$ 7.2) for $2 \mathrm{~h}$ and then post fixed with $1 \%$ osmium tetroxide in the same buffer. The fixed cells were dehydrated in a series of increasing ethanol concentrations (30-95\%) for $15 \mathrm{~min}$ and then in $100 \%$ ethanol for $20 \mathrm{~min}$. The cells were substituted with absolute isoamyl acetate for $15 \mathrm{~min}$ and air-dried. The cells were coated with gold by using a gold sputter coater and examined with a Hitachi S.2500C (Hitachi Co., Japan) scanning electron microscopy.

\section{- RESULTS AND DISCUSSION}

\section{Analysis of Growth on 2,2-DCP Minimal Medium and Chloride Ion Released}

The bacteria were screened on solid media containing $10 \mathrm{mM}$ 2,2-DCP as a carbon source. After 7 days incubation, a pure colony was observed on $10 \mathrm{mM}$ 2,2-DCP solid minimal medium. This colony was then grown in $10 \mathrm{mM}$ 2,2-DCP liquid minimal medium. The bacterium showed the ability to utilize 2,2-DCP as sole source of carbon under aerobic conditions with doubling time of approximately $13 \mathrm{~h}$ (Fig. 2). Analysis of the chloride ions released was also determined with the maximum chloride released estimated at $19.8 \mu \mathrm{mol} \mathrm{Cl} / / \mathrm{mL}$.

\section{S rDNA Gene Sequence Analysis}

The 16S rDNA PCR product showed that approximately 1500 bp DNA band was amplified. All the 1544 bp $16 \mathrm{~S}$ rDNA gene sequences were analyzed using BLASTn option (http:www.ncbi.nlm.nih.gov/BLAST/). The sequence matched with maximum identity of $99 \%$ to the bacterium Burkholderia pseudomallei (data not shown). Therefore, the current organism was designated as Burkholderia pseudomallei strain MF2.

Characterization based on biochemical properties and scanning electron microscopy (SEM) (Fig. 3) revealed the basic cellular morphology of the bacteria on

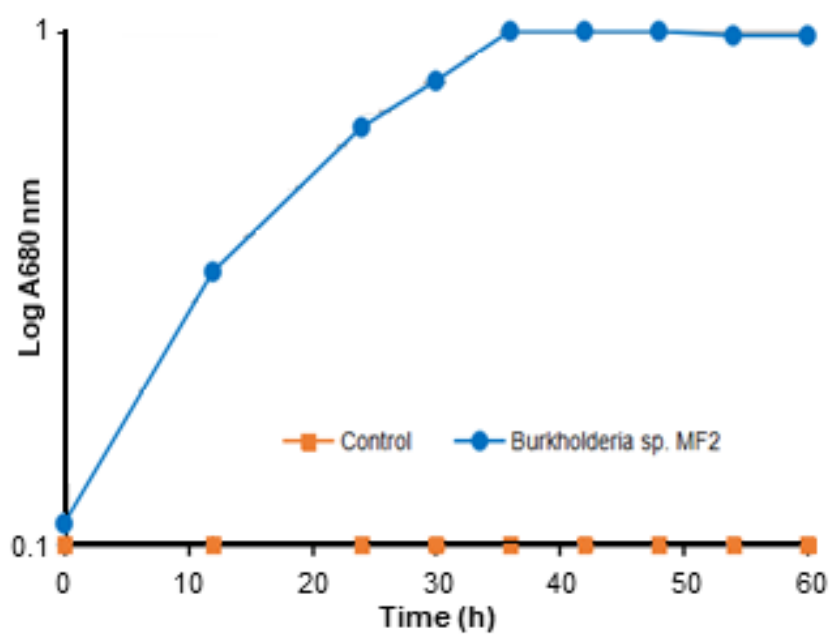

Fig 2. Maximum growth curve of Burkholderia sp. MF2 on $10 \mathrm{mM}$ 2,2-DCP minimal medium. Control (E. coli) showing no growth in $10 \mathrm{mM}$ 2,2-DCP minimal medium

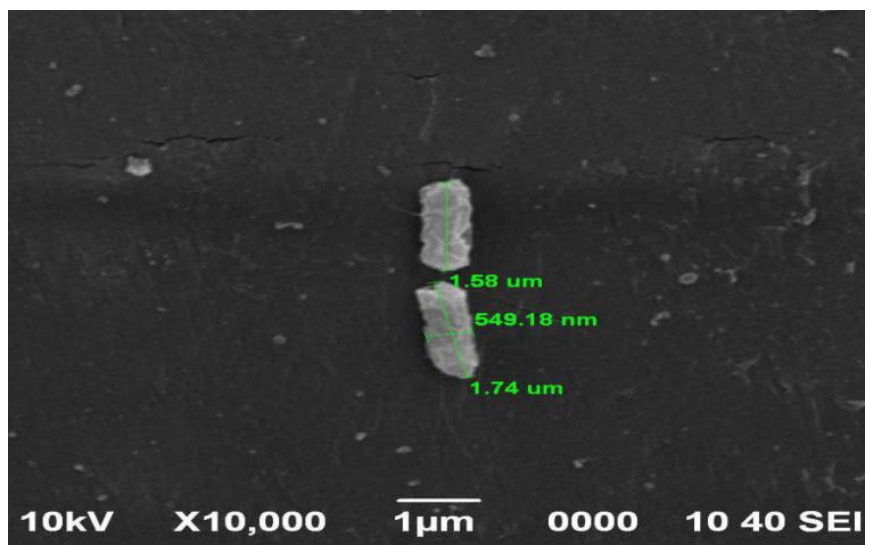

Fig 3. Electron microscopy analysis of strain MF2 appear as short rods with approximate length of 1.6-1.7 $\mu \mathrm{m}$; width $0.55 \mu \mathrm{m}(549 \mathrm{~nm})$ 
Table 3. Morphological and biochemical characterization of strain MF2

\begin{tabular}{ll}
\hline Properties & Details \\
\hline Cell shape & rod \\
Size & length of $1.6 \sim 1.7 \mu \mathrm{m}$; width $0.55 \mu \mathrm{m}$ \\
Colony morphology & Smooth, mucoid and somewhat elevated \\
Gram staining & Gram Negative \\
Spore staining & - \\
Oxygen requirement & Aerobic \\
Catalase & + \\
Oxidase & + \\
Urease & + \\
Gelatin hydrolysis & + \\
Citrate & + \\
Lactose utilization & - \\
Motility test & + \\
Nitrate reduction & - \\
Identity & Burkholderia sp. \\
\hline
\end{tabular}

+: positive, - : negative

solid minimal medium after 5 days incubation period at $30{ }^{\circ} \mathrm{C}$. The bacteria were rod-shaped with colonies showing smooth, mucoid and somewhat elevated edges. Gram staining confirmed that strain MF2 was rodshaped, Gram negative bacteria. Details of the physiological and biochemical properties of strain MF2 are depicted in Table 3.

\section{Amplification of Putative Dehalogenase Gene}

The PCR reaction was carried out as previously described and the PCR product was observed using gel electrophoresis. The result showed a single band of approximately $396 \mathrm{bp}$ was amplified using primers related to group I dehalogenase. On the other hand, no amplification of DNA band was detected for the group II dehalogenase and haloacetate dehalogenase H-2.

\section{Sequencing and Analysis of Putative Dehalogenase Gene}

The partial sequence of putative dehalogenase was successfully sequenced and analyzed showing $360 \mathrm{bp}$ DNA sequence (Fig. 4). The DNA Open Reading Frame (ORF) is a graphical analysis tool that can be used to find possible functional structural genes. The ORF Finder encodes for 120 amino acids only. The deduced sequence was short without start and stop codon. In order to check the identity of the current amino acids, multiple sequence analysis was carried out among both

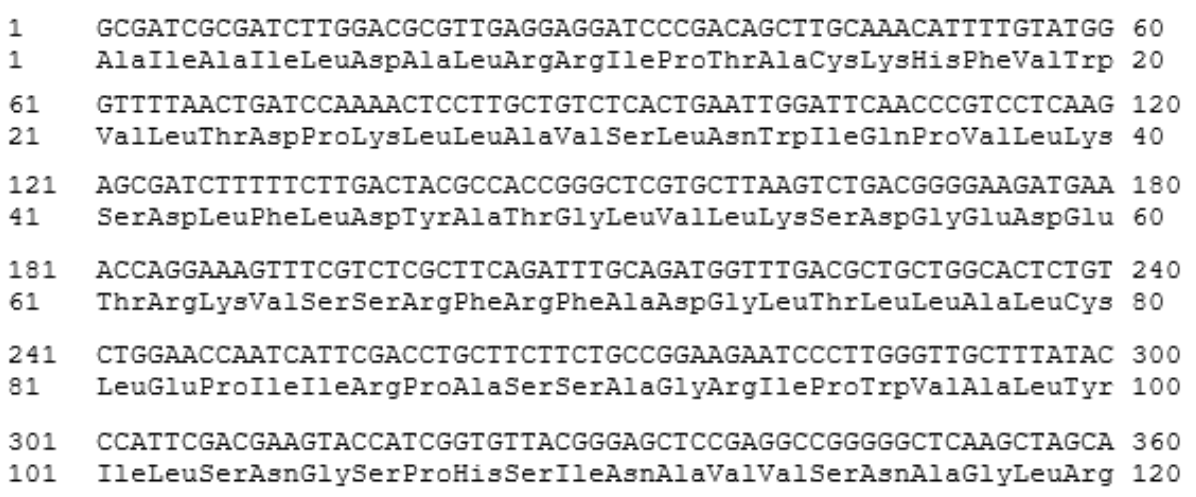

Fig 4. Partial sequence of nucleotide and deduced amino acid of putative dehalogenase from strain MF2 
groups I and II dehalogenases. The results showed there were no sequence identities with the known dehalogenases either group I or II, suggesting current isolate might be of a different kind of dehalogenase group. However, further analysis is needed to re-confirm this.

Burkholderia sp. can be found in the natural environment, such as soils, rhizospheres, water and from infected humans by melioidosis [23-26]. Very few halogenated aliphatic acids supported growth of the organisms. According to Watanabe et al. [27], there are differences between the bacteria isolated in the laboratory by enrichment and the bacteria performing the biodegradation in situ. The bacteria involved in biodegradation tend to be neglected more often when investigating pure culture isolates, since they are not always enriched in the process [28].

Burkholderia pseudomallei strain MF2 that was isolated from mud soil could grow on 2,2-DCP as sole source of carbon and energy. To allow growth on 2,2DCP, there are some basic criteria to be fulfilled. First, the organism must either possess or synthesize dehalogenase which is capable of removing the substituent halogen(s) from halogenated compounds. Next, the dehalogenation product should be non-toxic and easily converted to an intermediate via the organism's central metabolic pathway. The halogenated compound should be able to enter cells either passively or by active transport in order to reach the site of dehalogenase activity. Last but not least, the halogenated compound should be non-toxic to the organism at normal intracellular concentrations [11].

This study sequenced the $1.5-\mathrm{kb} 16 \mathrm{~S}$ rDNA gene. The results of the sequence was analyzed by sequence comparisons to the sequence in the NCBI database. The phylogenetic analysis of $16 \mathrm{~S}$ rDNA nucleotide sequence suggests the identity of the current isolate. Morphological and biochemical tests showed that MF2 is a rod-shaped Gram-negative bacteria. Based on the Bergey's manual of determinative bacteriology [18], the biochemical test supported the $16 \mathrm{~S}$ rDNA indicating that strain MF2 belongs to the genus Burkholderia sp.

Cells doubling time of MF2 was calculated to be 13 $\mathrm{h}$ in $10 \mathrm{mM}$ 2,2-DCP with concomitant release of chloride ions in the growth medium. The growth was relatively slower than that of Serratia sp [29], and more or less similar to the growth of Rhizobium sp. [30]. MF2 utilized 2,2-DCP as sole carbon source and it was believed to have eliminated the chlorine atom from the halogenated compound and produced pyruvate as a main product similar to what has been reported earlier by Slater et al. [11]. The maximum chloride ion released was $19.8 \mu \mathrm{mol} \mathrm{Cl}-/ \mathrm{mL}$, with almost all carbon source consumed after $42 \mathrm{~h}$ growth. It can be said that the MF2 strain exhibit a rather slow rate of 2,2-DCP utilization which could be attributed to a poor uptake system and/or low expression of the dehalogenase enzyme [31-35].

PCR amplification was used to detect partial dehalogenase genes. Group I deh genes, are specific towards both $\mathrm{D}$ and $\mathrm{L}$ forms of the substrate while group II deh genes are only active on the L form. Successful amplification of the putative dehalogenase gene was obtained using primers from group I suggesting the dehalogenase from MF2 might fall in the same category. In contrast, Bagherbaigi et al. [36] reported that strain S1 grew well on $\alpha / \beta$-haloalkanoic acids ( $\alpha / \beta$-HA) and only group II primers [22] from Xanthobacter autotrophicus - dhlB314 and dhlB637 showed amplification. This observation was possibly due to L-2-haloacid dehalogenases being more common than group I dehalogenases. On the other hand, two possible reasons why using group I primers could not amplify the S1 gene: (1) the primers might not be universal for some bacteria, and (2) only a single dehalogenase gene may be present that acts on both $\alpha \mathrm{HA}$ and $\beta \mathrm{HA}$.

Rhizobium sp. RC1 was reported to contain more than one dehalogenase [34-35]. DehE or D,L-haloacid dehalogenase from Rhizobiumsp. RC1 is unique because it can act on chiral carbons of both enantiomers. It is curious why Rhizobium sp. RC1 has more than one dehalogenases, when DehE alone can act on all of the substrates that DehD and DehL can also act on. Our current findings suggested that only a single dehalogenase may be present based on an in silico study by docking simulation [16,37-39]. Based on these findings, it can be inferred that some key catalytic residues of DehE is similar to that of dehalogenase of $S 1$ that can grow on $3 \mathrm{CP}$. However, more work involving 
gene cloning and protein analysis are required for further characterization.

\section{- CONCLUSION}

In conclusion, a molecular approach can be used to screen new genes of interest provided that the specific universal primers has no limitation. This study is the first study to investigate the presence of a putative dehalogenase gene in Burkholderia pseudomallei strain MF2 isolated from mud soil, associated with growth on 2,2-DCP or aHA. Using molecular tools, primers belonging to group I or II dehalogenases are possibly able to probe dehalogenase gene(s) present in the newly isolated microorganisms in the soil community.

\section{- ACKNOWLEDGMENTS}

Yilmaz Kaya and Fahrul Huyop would like to thank, The Scientific Technological Research Council of Turkey (TUBITAK), Program 2221 - Fellowships for Visiting Scientists and Scientists on Sabbatical Leave and Grant number 1059B211800242 for partly sponsoring this research. MFE and HMA thanks the Scientific Technological Research Council of Turkey (TUBITAK), Program 2216 - Research Fellowship Program for International Researchers Grant number 1059B211800242 for partly supporting this research. YK would like to thank Ondokuz Mayis University for joint financial support of the project (PYO.ZRT.1911.15.001).

\section{- REFERENCES}

[1] Rieger, P.G., Meier, H.M., Gerle, M., Vogt, U., Groth, T., and Knackmuss, H.J., 2002, Xenobiotics in the environment: Present and future strategies to obviate the problem of biological persistence, J. Biotechnol., 94 (1), 101-123.

[2] van Pée, K.H., and Unversucht, S., 2003, Biological dehalogenation and halogenation reactions, Chemosphere, 52 (2), 299-312.

[3] Karpouzas, D.G., and Singh, B.K., 2006, Microbial degradation of organophosphorus xenobiotics: Metabolic pathways and molecular basis, $A d v$. Microb. Physiol., 51, 119-225.

[4] Huyop, F., Yusn, T.Y., Ismail, M., Wahab, R.A., and Cooper, R.A., 2004, Overexpression and characterisation of non-stereospecific haloacid dehalogenase E (DehE) of Rhizobium sp, Asia Pac. J. Mol. Biol. Biotechnol., 12 (1-2), 15-20.

[5] Huyop, F., Jing, N.H., and Cooper, R.A., 2008, Overexpression, purification and analysis of dehalogenase D of Rhizobium sp, Can. J. Pure Appl. Sci., 2 (2), 389-392.

[6] Edbeib, M.F., Wahab, R.A., and Huyop, F., 2016, Characterization of an $\alpha$-haloalkanoic aciddegrading Pseudomonas aeruginosa MX1 isolated from contaminated seawater, Biorem. J., 20 (2), 8997.

[7] Leasure, J.K., 1964, Metabolism of herbicides, halogenated aliphatic acids, J. Agric. Food Chem., 12 (1), 40-43.

[8] Sinha, S., Chattopadhyay, P., Pan, I., Chatterjee, S., Chanda, P., Bandyopadhyay, D., Das, K., and Sen, S.K., 2009, Microbial transformation of xenobiotics for environmental bioremediation, Afr. J. Biotechnol., 8 (22), 6016-6027.

[9] Edbeib, M.F., Wahab, R.A., Kaya, Y., and Huyop, F., 2017, In silico characterization of a novel dehalogenase (DehHX) from the halophile Pseudomonas halophila HX isolated from Tuz Gölü Lake, Turkey: Insights into a hypersaline-adapted dehalogenase, Ann. Microbiol., 67 (5), 371-382.

[10] Schwarze, R., Brokamp, A., and Schmidt, R.J.F., 1997, Isolation and characterization of dehalogenases from 2,2-dichloropropionate-degrading soil bacteria, Curr. Microbiol., 34 (2), 103-109.

[11] Slater, J.H., Bull, A.T., and Hardman, D.J., 1996, Microbial dehalogenation of halogenated alkanoic acids, alcohols and alkanes, Adv. Microb. Physiol., 38, 133-176.

[12] Hill, K.E., Marchesi, J.R., and Weightman, A.J., 1999, Investigation of two evolutionarily unrelated halocarboxylic acid dehalogenase gene families, $J$. Bacteriol., 181 (8), 2535-2547.

[13] Kawasaki, H., Tsuda, K., Matsushita, I., and Tonomura, K., 1992, Lack of homology between two haloacetate dehalogenase genes encoded on a plasmid from Moraxella sp. strain B, J. Gen. Microbiol., 138 (7), 1317-1323. 
[14] Adamu, A., Wahab, R.A., Shamsir, M.S., Aliyu, F., and Huyop, F., 2017, Deciphering the catalytic amino acid residues of 1-2-haloacid dehalogenase (DehL) from Rhizobium sp. RC1: An in silico analysis, Comput. Biol. Chem., 70, 125-132.

[15] Adamu, A., Shamsir, M.S., Wahab, R.A., Parvizpour, S., and Huyop, F., 2017, Multi-template homologybased structural model of L-2-haloacid dehalogenase (DehL) from Rhizobium sp. RC1, J. Biomol. Struct. Dyn., 35 (15), 3285-3296.

[16] Nemati, M., Abdulghader, H.F., Gicana, R.G., Lamis, R.J.S., Ibrahim, N., Hamid, A.A.A., and Huyop, F.Z., 2013, Identification of putative Cof-like hydrolase associated with dehalogenase in Enterobacter cloacae MN1 isolated from the contaminated sea-side area of the Philippines, Malays. J. Microbiol., 9 (3), 253-259.

[17] Hamid, A.A.A., Hamdan, S., Ariffin, S.H., and Huyop, F., 2010, Molecular prediction of dehalogenase producing microorganism using $16 \mathrm{~S}$ rDNA analysis of 2,2-dichloropropionate (Dalapon) degrading bacterium isolated from volcanic soil, $J$. Biol. Sci., 10 (3), 190-199.

[18] Bergey, D.H., and Holt, J.G., 1994, Bergey's Manual of Determinative Bacteriology, $9^{\text {th }}$ Ed., Williams and Wilkins, Baltimore.

[19] Alomar, D., Hamid, A.A.A., Khosrowabadi, E., Gicana, R.G., Lamis, R.J., Huyop, F., and Tengku Abdul Hamid, T.H., 2014, Molecular characterization of monochloroacetate-degrading Arthrobacter sp. strain D2 isolated from Universiti Teknologi Malaysia agricultural area, Biorem. J., 18 (1), 12-19.

[20] Bergmann, J., and Sanik, J.J., 1957, Determination of trace amounts of chlorine in naphtha, Anal. Chem., 29 (2), 241-243.

[21] Fulton, C.K., and Cooper, R.A., 2005, Catabolism of sulfamate by Mycobacterium sp. CF1, Environ. Microbiol., 7 (3), 378-381.

[22] van der Ploeg, J., van Hall, G., and Janssen, D.B., 1991, Characterization of the haloacid dehalogenase from Xanthobacter autotrophicus $\mathrm{GJ} 10$ and sequencing of the dhlB gene, J. Bacteriol., 173 (24), 7925-7933.
[23] Fortin, N., Fulthorpe, R.R., Allen, D.G., and Greer, C.W., 1998, Molecular analysis of bacterial isolates and total community DNA from kraft pulp mill effluent treatment systems, Can. J. Microbiol., 44 (6), 537-546.

[24] Dance, D.A.B., Limmathurotsakul, D., and Currie, B.J., 2017, Burkholderia pseudomallei: Challenges for the clinical microbiology laboratory-A response from the front line, J. Clin. Microbiol., 55 (3), 980982.

[25] Vial, L., Chapalain, A., Groleau, M.C., and Déziel, E., 2011, The various lifestyles of the Burkholderia cepacia complex species: A tribute to adaptation, Environ. Microbiol., 13 (1), 1-12.

[26] Coenye, T., and Andamme, P., 2003, Diversity and significance of Burkholderia species occupying diverse ecological niches, Environ. Microbiol., 5 (9), 719-729.

[27] Watanabe, K., Teramoto, M., Futamata, H., and Harayama, S., 1998, Molecular detection, isolation, and physiological characterization of functionally dominant phenol-degrading bacteria in activated sludge, Appl. Environ. Microbiol., 64 (11), 4396-4402.

[28] Watanabe, K., and Baker, P.W., 2000, Environmentally relevant microorganisms, $J$. Biosci. Bioeng., 89 (1), 1-11.

[29] Abel, E., Ibrahim, N., and Huyop, F., 2012, Identification of Serratia marcescens SE1 and determination of its herbicide 2,2dichloropropionate (2,2-DCP) degradation potential, Malays. J. Microbiol., 8 (4), 259-264.

[30] Allison, N., Skinner, A.J., and Cooper, R.A., 1983, The dehalogenases of a 2,2-dichloropropionatedegrading bacterium, J. Gen. Microbiol., 129 (5), 1283-1293.

[31] Abel, E., Ibrahim, N., and Huyop, F., 2012, Identification of Serratia marcescens SE1 and determination of its herbicide 2,2dichloropropionate (2,2-DCP) degradation potential, Malays. J. Microbiol., 8 (4), 259-264.

[32] Abel, E., Pakingking Jr., R.V., Pagador, G., Wint, M.T., and Huyop, F., 2012, Characteristics of 
dehalogenase from bacteria isolated from the gut of pond-reared rohu (Labeo rohita) Juveniles in Myanmar, Adv. Biosci. Biotechnol., 3, 353-361.

[33] Jing, N.H., Wahab, R.A., Hamdan, S., and Huyop, F., 2010, Cloning and DNA sequence analysis of the alhoalkanoic permease uptake gene from Rhizobium sp. RC 1, Biotechnology, 9 (3), 319-325.

[34] Su, X., and Tsang, J.S.H., 2013, Existence of a robust haloacid transport system in a Burkholderia species bacterium, Biochim. Biophys. Acta, Biomembr., 1828 (2), 187-192.

[35] Musa, M.A., Wahab, R.A., and Huyop, F., 2018, Homology modelling and in silico substrate-binding analysis of a Rhizobium sp. RC1 haloalkanoic acid permease, Biotechnol. Biotechnol. Equip., 32 (2), 339349.

[36] Bagherbaigi, S., Gicana, R.G., Lamis, R.J., Nemati, M., and Huyop, F., 2013, Characterisation of Arthrobacter sp. S1 that can degrade $\alpha$ and $\beta$ haloalkanoic acids isolated from contaminated soil,
Ann. Microbiol., 63 (4), 1363-1369.

[37] Cairns, S.S., Cornish, A., and Cooper, R.A., 1996, Cloning, sequencing and expression in Escherichia coli of two Rhizobium sp. genes encoding haloalkanoate dehalogenases of opposite stereospecificity, Eur. J. Biochem., 235 (3), 744-749.

[38] Hamid, A.A.A., Wong, E.L., Joyce-Tan, K.H., Shamsir, M.S., Tengku Abdul Hamid, T.H., and Huyop, F., 2013, Molecular modelling and functional studies of the non-stereospecific $\alpha$ haloalkanoic acid dehalogenase (DehE) from Rhizobium sp. RC1 and its association with 3chloropropionic acid ( $\beta$-chlorinated aliphatic acid), Biotechnol. Biotechnol. Equip., 27 (2), 3725-3736.

[39] Batumalaie, K., Edbeib, M.F., Mahat, N.A., Huyop, F., and Wahab, R.A., 2018, In silico and empirical approaches toward understanding the structural adaptation of the alkaline-stable lipase KV1 from Acinetobacter haemolyticus, J. Biomol. Struct. Dyn., 36 (12), 3077-3093. 